\title{
Modeling Solid-Electrolyte Interfacial Phenomena in Silicon Anodes
}

F. A. Soto ${ }^{1}$, J. M. Martinez de la Hoz ${ }^{1,2}$, J. M. Seminario ${ }^{1}$, and P. B. Balbuena ${ }^{1 *}$

${ }^{1}$ Department of Chemical Engineering, Texas A\&M University, College Station, TX 77843, USA,

${ }^{2}$ Current address: The Dow Chemical Company, 2301 N. Brazosport Blvd., Freeport, TX 77541

*e-mail: balbuena@tamu.edu

\begin{abstract}
Silicon shows promising characteristics to replace graphite as the anode material in Li-ion batteries (LIBs). However addressing the volume changes in silicon during lithiation and the formation of the solid-electrolyte interphase (SEI) at the silicon-based anodes are essential to make this a practical technology. The electrolyte decomposition can lead to a continuous growth of the SEI layer; which in turn serves a double purpose: passivation of the anode surface and barrier for the $\mathrm{Li}^{+}$diffusion. Despite the great importance of the SEI in Si-based anodes on the cycling performance of the LIBs, a deeper understanding of the SEI evolution, composition, and morphology is still lacking. In this article, we briefly review the recent findings in the field of computational materials science regarding the initial stages and growth of the SEI layer on silicon anodes.
\end{abstract}

\section{Introduction}

Energy storage devices such as batteries are necessary for the advancement of Plugless electric vehicles (EVs), low-power battery-on-a-chip, electricity storage in distribution networks, portable electronics and so forth. Due to the market penetration of rechargeable batteries in the automotive industry, the United States Advanced Battery Council (USABC) has established long-term goals that demand batteries to provide EVs with driving ranges greater than 200 miles and a battery life greater than 100,000 miles (2016, www.uscar.org). Lithium-ion batteries (LIBs) are suitable candidates to drive the technology to harvest a higher energy density to 
power portable devices and EVs. A typical electrochemical cell for this system includes graphitelithium cobalt oxide $\left(\mathrm{LiCoO}_{2}\right)$ with lithium hexafluorophosphate $\left(\mathrm{LiPF}_{6}\right)$ and organic solvents as the electrolyte mixture [1,2]. Graphite has replaced lithium metal as the anode electrode material due to the uncontrollable dendritic Li growth and limited Coulombic efficiency (C.E.) during Li deposition/stripping in Li metal anode-based batteries [3-9]. In the graphite anode-based batteries, graphite has a Li charge storage capacity of $372 \mathrm{mAh} / \mathrm{g}$ (with a theoretical capacity of up to one $\mathrm{Li}^{+}$for every six carbon atoms, $\left.\mathrm{LiC}_{6}\right)$ [10]. Hence, the combination of these standard materials results in a relatively low voltage (i.e. $3.4 \mathrm{eV}$ ) which is deemed insufficient for EV's battery packs. It is widely known that modern cathode materials such as $\mathrm{LiCoO}_{2}$, lithium manganese oxide $\left(\mathrm{LiMn}_{2} \mathrm{O}_{4}\right)$, and lithium iron phosphate $\left(\mathrm{LiFePO}_{4}\right)$ are limited to intercalation/insertion compounds [11]. Thus, any considerable improvement in the electrode must be made of the anode material. Finding a suitable anode material is an effective way to solve the problem related to Li dendrite growth and to improve Li resource utilization [5,12-15]. Specifically, LIBs consisting of a transition metal oxide cathode and a silicon anode are a promising solution due to their potentially high energy and power density $[16,17]$.

Silicon ( $\mathrm{Si}$ ) as an anode material offers a tenfold increase in capacity per unit weight (4200 $\mathrm{mAh} / \mathrm{g}$, lithiated to $\mathrm{Li4} 4 \mathrm{Si}$ ) when compared to the widely-used graphite anode [18-22]. Furthermore, the lithiation voltage plateau $\left(0.2-0.3 \mathrm{~V}\right.$ vs. $\left.\mathrm{Li}^{-} \mathrm{Li}^{+}\right)$for $\mathrm{Si}$ could prevent lithium plating, dendrite formation, and growth $[19,23]$. Despite these improvements over graphite, it is still a significant challenge to implement $\mathrm{Si}$ as an anode in LIBs due to the volume change that takes place during cycling (up to four times its volume when charged with lithium ions) which leads to low C.E. and poor capacity retention [24-27]. On the other hand, the reaction mechanisms that result in the decomposition of the electrolyte and simultaneous solid-electrolyte 
interphase (SEI) formation remain elusive. This article briefly summarizes the computational research activities in the field of LIBs with $\mathrm{Si}$ as an anode material and reports recent works and improvements on this subject. We emphasize the study of LIBs with Si anodes on the formation (i.e. understanding of the processes that lead to electrolyte decomposition at the Si surface) and growth of the SEI layer.

\section{Reactions at the Si Anode/Electrolyte Interphase}

\section{Solvent Decomposition at the Lithiated Si Surface}

Martinez de la Hoz, Balbuena, and co-workers [28•,29•,30•] studied the interaction of electrolyte molecules with lithiated Si anodes, using ab-initio molecular dynamics (AIMD) simulations. First, reduction mechanisms of the ethylene carbonate (EC) solvent molecule and those of the additives fluoroethylene carbonate (FEC) and vinylene carbonate (VC) were determined as a function of the lithiation degree of the $\mathrm{Si}$ anode. It is important to note that as the $\mathrm{Li} / \mathrm{Lix}_{\mathrm{x}} \mathrm{Si}_{\mathrm{y}}$ cell is cycled experimentally at high temperatures, potential plateaus at $0.39 \mathrm{~V}, 0.37 \mathrm{~V}, 0.26 \mathrm{~V}$, and 0.1 $\mathrm{V}$ are found, indicating the formation of $\mathrm{LiSi}_{1} \mathrm{Li}_{12} \mathrm{Si}_{7}, \mathrm{Li}_{7} \mathrm{Si}_{3}$, and $\mathrm{Li}_{13} \mathrm{Si}_{4}$, respectively $[31,32]$. Although ionic conductivity through the SEI should not be severely affected by the presence of oligomers, these species have been shown to be electrochemically unstable. This lack of stability of the oligomer phase would result in the continuous SEI growth and subsequent cell capacity fading.

The computational results showed that the degree of Si lithiation exerts a substantial effect on the reduction mechanism of EC molecules (see Figure 1). Also, the decomposition of EC may start at very early stages of lithiation (voltages $>0.39 \mathrm{~V} \mathrm{vs.} \mathrm{Li}^{+} / \mathrm{Li}$ metal) after the initial electron transfer from the surface to the adsorbed molecule or intact/open molecules in the liquid phase. 

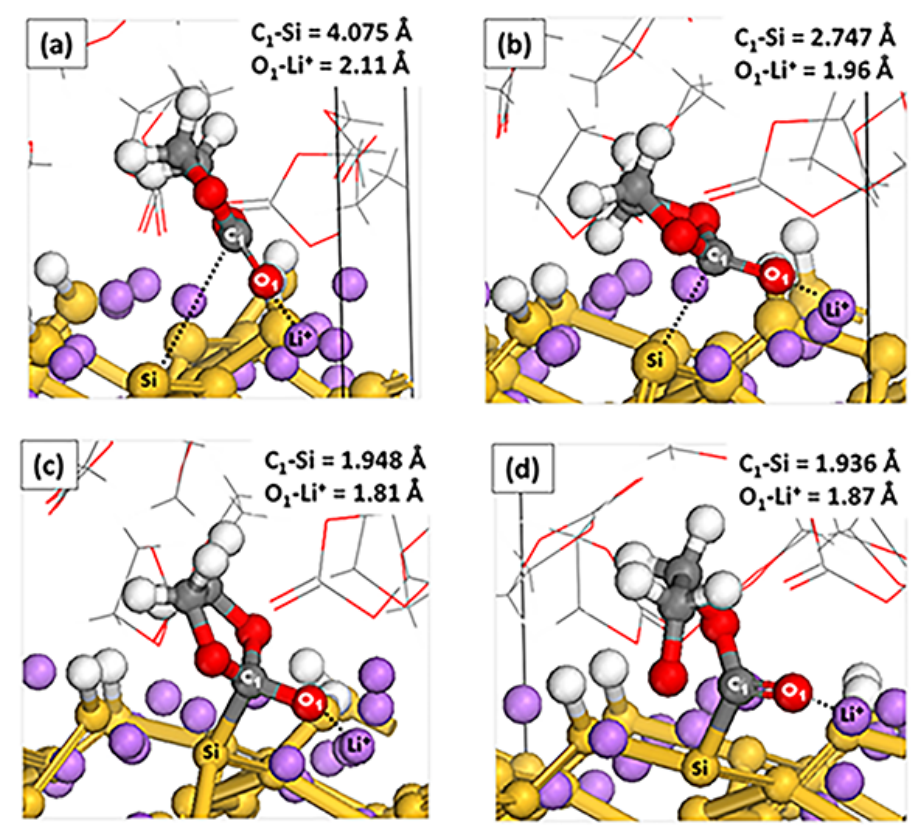

Figure 1. Panels are showing the decomposition of EC molecules at the lithiated Si surface. Reproduced with permission from [28•], copyright (C) 2013 American Chemical Society. Color code: Yellow, purple, white, gray, and red spheres represent $\mathrm{Si}, \mathrm{Li}, \mathrm{H}, \mathrm{C}$, and $\mathrm{O}$ atoms, respectively.

In the latter case, a simultaneous transference of two electrons from the surface to an adsorbed EC molecule yields the $\mathrm{O}\left(\mathrm{C}_{2} \mathrm{H}_{4}\right) \mathrm{OCO}^{2-}$ adsorbed species. In the first instance, a sequential twoelectron transfer takes place in the liquid phase, yielding the $\mathrm{C}_{2} \mathrm{H}_{4} / \mathrm{CO}_{3}{ }^{2-}$ pair. On the other hand, reduction of EC molecules on strongly lithiated silicon anodes ( $\left.\mathrm{Li}_{13} \mathrm{Si}_{4}\right)$ takes place through a four-electron mechanism, generating an adsorbed $\mathrm{CO}^{2-}$ and the $\mathrm{O}\left(\mathrm{C}_{2} \mathrm{H}_{4}\right) \mathrm{O}^{2-}$ fragment in the liquid phase. Transference of two electrons to EC molecules in the liquid phase was also observed on $\mathrm{Li}_{13} \mathrm{Si}_{4}$, resulting in $\mathrm{O}\left(\mathrm{C}_{2} \mathrm{H}_{4}\right) \mathrm{OCO}^{2-}$ anions and $\mathrm{C}_{2} \mathrm{H}_{4} / \mathrm{CO}_{3}{ }^{2-}$ pairs in the liquid phase. Regarding the additives, we showed that FEC selectively decomposes over diethyl carbonate (DEC) and EC by a comparatively high rate leading to the formation of $\mathrm{LiF}[29 \bullet, 30 \bullet]$. Moreover, FEC reduction on $\mathrm{Li}_{\mathrm{x}} \mathrm{Si}_{\mathrm{y}}$ surfaces was found to be independent of the degree of lithiation and occurs through three mechanisms [29•]. One of them leads to an adsorbed $\mathrm{VC}^{2-}$ 
anion upon release from the FEC molecule and adsorption on the surface of one $\mathrm{F}^{-}$and one $\mathrm{H}$ atom. Thus in some cases, the reduction of FEC may lead to the same reduction products as those of VC, which explains similarities in SEI layers formed in the presence of these additives. However, FEC may be reduced via two other multi-electron transfer mechanisms that result in the formation of either $\mathrm{CO}_{2}{ }^{2-}, \mathrm{F}$, and $\mathrm{CH}_{2} \mathrm{CHO}^{-}$or $\mathrm{CO}^{2-}, \mathrm{F}$, and $\mathrm{OCH}{ }_{2} \mathrm{CHO}^{-}$. These alternative reduction products may oligomerize and form SEI layers with different components than those formed in the presence of VC. Meanwhile, reduction of $\mathrm{VC}$ at low and intermediate lithiation stages ( $\mathrm{LiSi} 2$ and $\mathrm{LiSi}$ ), proceeds via a two-electron mechanism, which yields an opened $\mathrm{VC}^{2-}$ anion adsorbed on the Si surface. At higher degrees of lithiation $\left(\mathrm{Li}_{13} \mathrm{Si}_{4}\right)$, such a species receives two extra electrons from the surface resulting in an adsorbed $\mathrm{CO}^{2-}$ anion and the radical anion $\mathrm{OC}_{2} \mathrm{H}_{2} \mathrm{O}^{2-}$. It is important to note that even though carbonate-based electrolytes are still the standard for LIBs other electrolytes such as ionic liquid electrolytes (ILs)[33] and polymer electrolytes have recently been investigated for silicon anode [34].

\section{Electrolyte Mixture Decomposition at the Lithiated Si Surface}

More recently, we explored the effect of electrolyte composition (e.g. EC, $50 \%$ wt. FEC, and LiPF6) on SEI formation on highly lithiated Si anodes [30•]. Here, seven EC molecules, six FEC molecules, and one LiPF6 salt were placed in contact with the Li13Si4 anode surface (Fig. 2, left). 

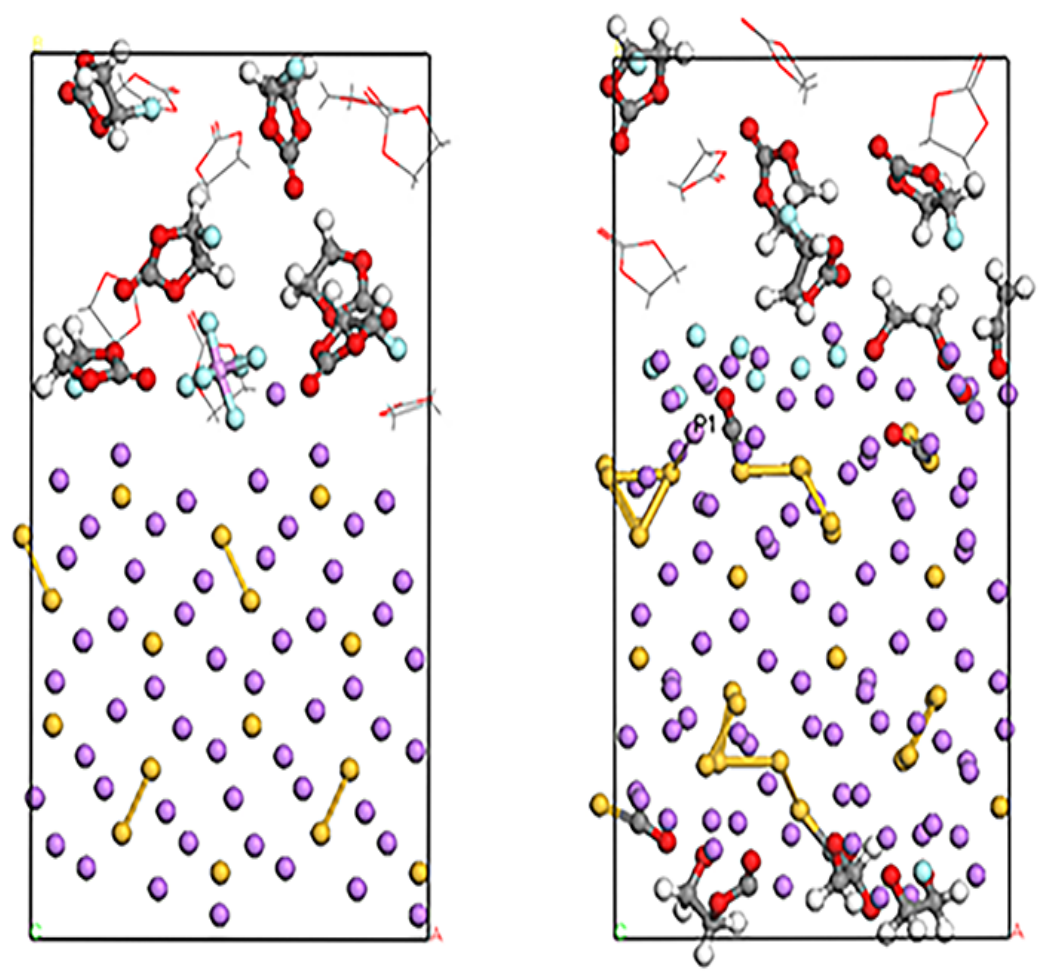

Figure 2. Left: Initial configuration used for AIMD simulation of EC/FEC/LiPF6 mixture. Right: Configuration of the system after 17254 fs of simulation, undecomposed EC molecules are depicted as stick figures. Reproduced with permission from [30•], copyright (C) 2015 American Chemical Society. Color code: Yellow, purple, white, gray, red, blue, and orange spheres represent $\mathrm{Si}, \mathrm{Li}, \mathrm{H}, \mathrm{C}, \mathrm{O}, \mathrm{F}$, and $\mathrm{P}$ atoms, respectively.

Figure 2 (right) shows the configuration of the system at the end of the simulation. Two EC molecules decomposed with the following reaction:

$$
\mathrm{EC}+2 \mathrm{e}^{-} \longrightarrow \mathrm{O}\left(\mathrm{C}_{2} \mathrm{H}_{4}\right) \mathrm{O}^{2-}+\mathrm{CO}_{(\mathrm{ads})}
$$

and two EC molecules decomposed following:

$$
\mathrm{EC}+2 \mathrm{e}^{-} \longrightarrow \mathrm{O}\left(\mathrm{C}_{2} \mathrm{H}_{4}\right) \mathrm{OCO}^{2-}
$$

Also, one of the FEC molecules reduced according to the following mechanism:

$$
\begin{aligned}
\mathrm{FEC}+2 \mathrm{e}^{-} & \longrightarrow \mathrm{OCO}\left(\mathrm{C}_{2} \mathrm{H}_{3}\right) \mathrm{FO}^{2-}{ }_{(\mathrm{ads})} \\
\mathrm{OCO}\left(\mathrm{C}_{2} \mathrm{H}_{3}\right) \mathrm{FO}^{2-}{ }_{(\mathrm{ads})} & \longrightarrow \mathrm{F}^{-}{ }_{(\mathrm{ads})}+\mathrm{OCO}\left(\mathrm{C}_{2} \mathrm{H}_{3}\right) \mathrm{O}^{-}{ }_{(\mathrm{ads})} \\
\mathrm{OCO}\left(\mathrm{C}_{2} \mathrm{H}_{3}\right) \mathrm{O}^{-}{ }_{(\mathrm{ads})}+2 \mathrm{e}^{-} & \longrightarrow \mathrm{CO}_{2}{ }^{2-}\left({ }_{\mathrm{ads}}\right)+\mathrm{C}_{2} \mathrm{H}_{3} \mathrm{O}^{-}
\end{aligned}
$$


Figure 3 follows P-F bond lengths in the salt as a function of time. Initially, three of the F atoms leave the $\mathrm{PF}_{6}{ }^{-}$group, almost simultaneously, after about 11200 fs of simulation time. The neutral $\mathrm{PF}_{3}$ group remains in the liquid phase for about 1300 fs. Subsequently, the $\mathrm{PF}_{3}$ group is adsorbed onto a $\mathrm{Si}$ atom of the surface, resulting in the subsequent total decomposition of the salt. Charges of the $\mathrm{PF}_{\mathrm{x}}$ group and the $\mathrm{P}$ atom during decomposition of the salt are shown in Figure 4 . The oxidation state of the $\mathrm{P}$ atom changes during the salt decomposition from +3.7 to -1.2 .

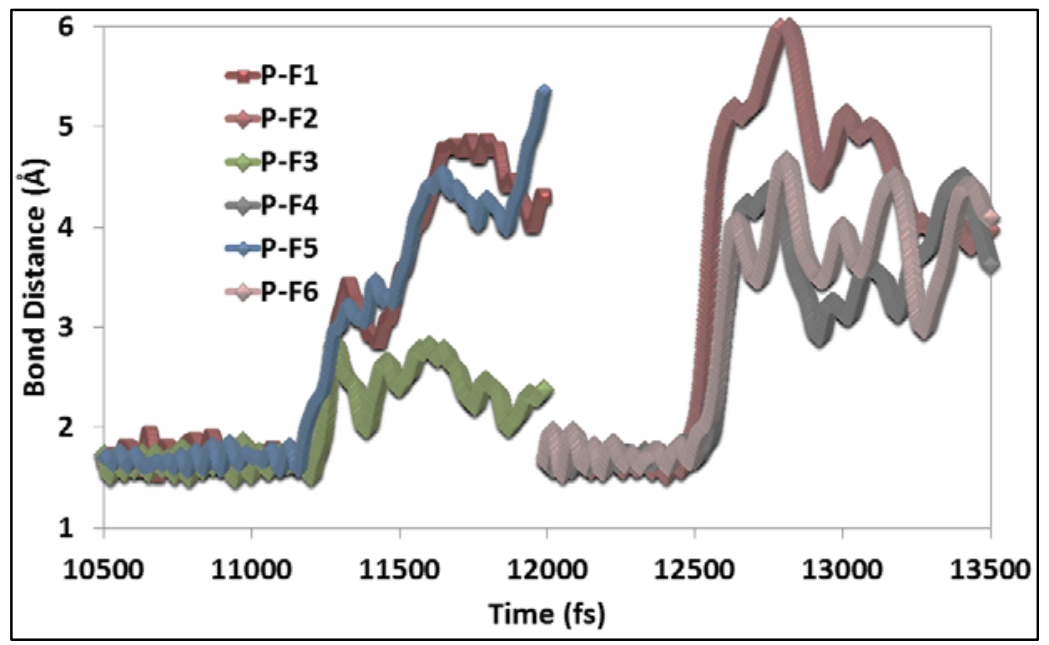

Figure 3. P-F bond distances in the LiPF6 salt as a function of time. Reproduced with permission from [30•], copyright (C) 2015 American Chemical Society. 


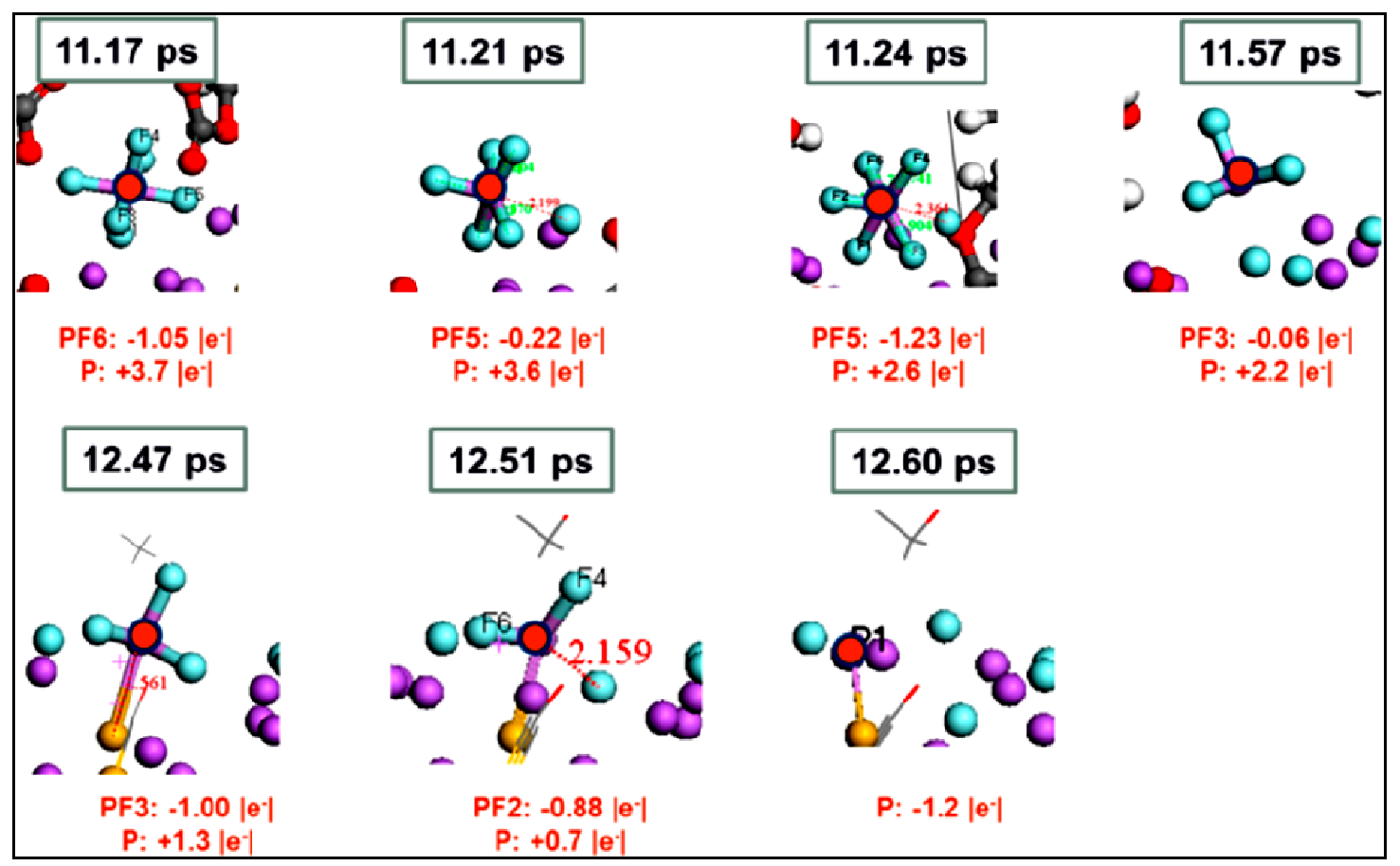

Figure 4. Evolution of $\mathrm{PF}_{\mathrm{x}}$ with time. Charges corresponding to the $\mathrm{PF}_{\mathrm{x}}$ group and the $\mathrm{P}$ atom are also shown. Reproduced with permission from [30•], copyright (C) 2015 American Chemical Society. Color code as in Figure 2.

Leung and coworkers employed AIMD simulations to study the reduction of a liquid EC-FEC mixture on both, a pristine $\mathrm{Li}_{13} \mathrm{Si}_{4}$ surface, and on a $\mathrm{Li}_{13} \mathrm{Si}_{4}$ surface covered with $\mathrm{a} \sim 7 \AA$ thin, stoichiometric $\mathrm{Li}_{4} \mathrm{SiO}_{4}$ layer [35]. This mixed oxide is known to be present after cycling $\mathrm{Si}$ anodes in LIBs, and its presence may slow down electron-transfer during initial charging cycles. FEC was found to dissociate rapidly ( $\sim 4$ ps of simulation) in the presence of pristine $\mathrm{Li}_{13} \mathrm{Si}_{4}$. Two-electron transfers from the surface yielded $\mathrm{CO}, \mathrm{F}^{-}$, and $\mathrm{C}_{2} \mathrm{H}_{3} \mathrm{O}_{2}{ }^{-}$products in the majority of the cases, in agreement with one of the reduction pathways reported by Martinez and Balbuena [29•]. The $\mathrm{F}^{-}$goes to the surface electrostatically interacting with $\mathrm{Li}^{+}$ions, and the $\mathrm{R}-\mathrm{CHO}-$ functional groups of the organic anionic fragments are reactive and may participate in further nucleophilic attacks. Additionally, one FEC molecule ejected an $\mathrm{F}^{-}$before any other bond breaking occurred. Subsequently, the $\mathrm{C}_{3} \mathrm{H}_{3} \mathrm{O}_{3}{ }^{-}$fragment initiated a nucleophilic attack on a neighboring EC molecule, which was proposed as the initiation of an oligomerization reaction. 
EC molecules were also found to undergo two-electron reductions, yielding $\mathrm{CO} / \mathrm{OC}_{2} \mathrm{H}_{4} \mathrm{O}^{2-}$ and $\mathrm{C}_{2} \mathrm{H}_{4} / \mathrm{CO}_{3}{ }^{2-}$ pairs. In the case in which $\mathrm{Li}_{4} \mathrm{SiO}_{4} / \mathrm{Li}_{13} \mathrm{Si}_{4}$ was used as the anode, two FEC were decomposed in picosecond time scales. Despite the expectation that the oxide should slow down electron transfer and enhance one-electron attacks on FEC over two-electron reductions, Bader charge decomposition analysis showed that the products are still consistent with two-electron induced reactions. Thus, the thin $(\sim 7 \AA)$ insulator oxide layers located between the metallic $\mathrm{Li}_{13} \mathrm{Si}_{4}$ and the electrolyte appears not sufficiently thick for slowing down electron-transfers.

\section{Understanding the SEI Layer Formation and Growth}

As the volume of the $\mathrm{Si}$ anode changes, a fresh $\mathrm{Si}$ surface is continually exposed to the electrolyte and the SEI layer continues to grow [24]. However, after a certain thickness, electron tunneling from the anode is hindered; thus, slowing down additional electrolyte decomposition while still allowing Li-ion migration between the anode and the electrolyte. For this reason, experimental and theoretical work aimed to control and understand the formation, composition, stability and growth of the SEI layer has been conducted recently $[36-48,49 \cdot, 50]$. Benitez et al. [51•] used a DFT/Green's function approach to characterize electron currents through the $\mathrm{Lix}_{\mathrm{x}} \mathrm{Si}_{\mathrm{y}-}$ anode/SEI/electrolyte composite film for some interfacial configurations. Three different degrees of lithitation were evaluated for the $\mathrm{Lix}_{x} \mathrm{Si}_{\mathrm{y}}$ electrode: $\mathrm{Si}, \mathrm{LiSi}$, and $\mathrm{Li}$. The SEI was composed by $\mathrm{LiF}$ or $\mathrm{Li}_{2} \mathrm{O}$, and the electrolyte was represented by EC solvent molecules. An applied potential was used as driving force for the leakage current, which was evaluated as a function of the applied potential. In all cases, current-potential curves were computed in a range of applied potentials from -5.5 to $5.5 \mathrm{~V}$. For both types of model composite systems investigated, $\mathrm{Lix}_{\mathrm{x}} \mathrm{Si}_{\mathrm{y}}-$ anode $/ \mathrm{LiF} / \mathrm{EC}$ and $\mathrm{Li}_{x} \mathrm{Si}_{y}$-anode $/ \mathrm{Li}_{2} \mathrm{O} / \mathrm{EC}$, the presence of the $\mathrm{SEI}$ layer created a clear resistance to electron transfer, evidenced by larger currents detected in bare electrode systems $\left(\mathrm{Li}_{\mathrm{x}} \mathrm{Si}_{\mathrm{y}}-\right.$ 
anode/EC). This result agrees with the accepted idea that the SEI layer blocks electron transfer. Regarding differences in conductivity between $\mathrm{Li}_{2} \mathrm{O}$ and $\mathrm{LiF}$, it was found that given the same thickness and configuration, $\mathrm{LiF}$ offers a higher resistance to electron transfer than $\mathrm{Li}_{2} \mathrm{O}$. This trend is in agreement with experimental band-gap values for these molecules, corresponding to 14.2 and $7.99 \mathrm{eV}$ for $\mathrm{LiF}$ and $\mathrm{Li}_{2} \mathrm{O}$, respectively. The effect of the lithiation degree on electron conductivity is also recognized, with maximum current values of $1.5,12$, and $15 \mu \mathrm{A}$ at the highest potential $(\sim 4 \mathrm{~V})$ for $\mathrm{Si}, \mathrm{LiSi}$, and $\mathrm{Li}$ respectively. Such trend also correlates with the electronic structure of $\mathrm{Si}$ (semiconducting), LiSi, and Li (metallic). Finally, the effect of the SEIthickness was evaluated. As expected, increasing SEI thickness results in higher resistance. Moreover, SEI thicknesses of about $1 \mathrm{~nm}$ still allow small finite currents through the composite systems. Benitez and coworkers approach proved useful for testing electron transfer through various SEI configurations. However, one crucial remaining question is how does the SEI layer grow after its thickness goes beyond electron tunneling lengths [49•]. In a recent work [49•], we used AIMD simulations on models containing lithium ethylene dicarbonate ( $\left.\mathrm{Li}_{2} \mathrm{EDC}\right)$ and lithium vinylene dicarbonate $\left(\mathrm{Li}_{2} \mathrm{VDC}\right)$ that mimicked an SEI layer (see Figure 5a) on top of a lithiated $\mathrm{Si}$ anode $\left(\mathrm{Li}_{13} \mathrm{Si}_{4} /\left(\mathrm{LiF}, \mathrm{Li}_{2} \mathrm{O}\right.\right.$, or $\left.\mathrm{Li}_{2} \mathrm{CO}_{3}\right) /\left(\mathrm{Li}_{2} \mathrm{EDC}\right.$ or $\left.\mathrm{Li}_{2} \mathrm{VDC}\right)$ to shed light on this question. 


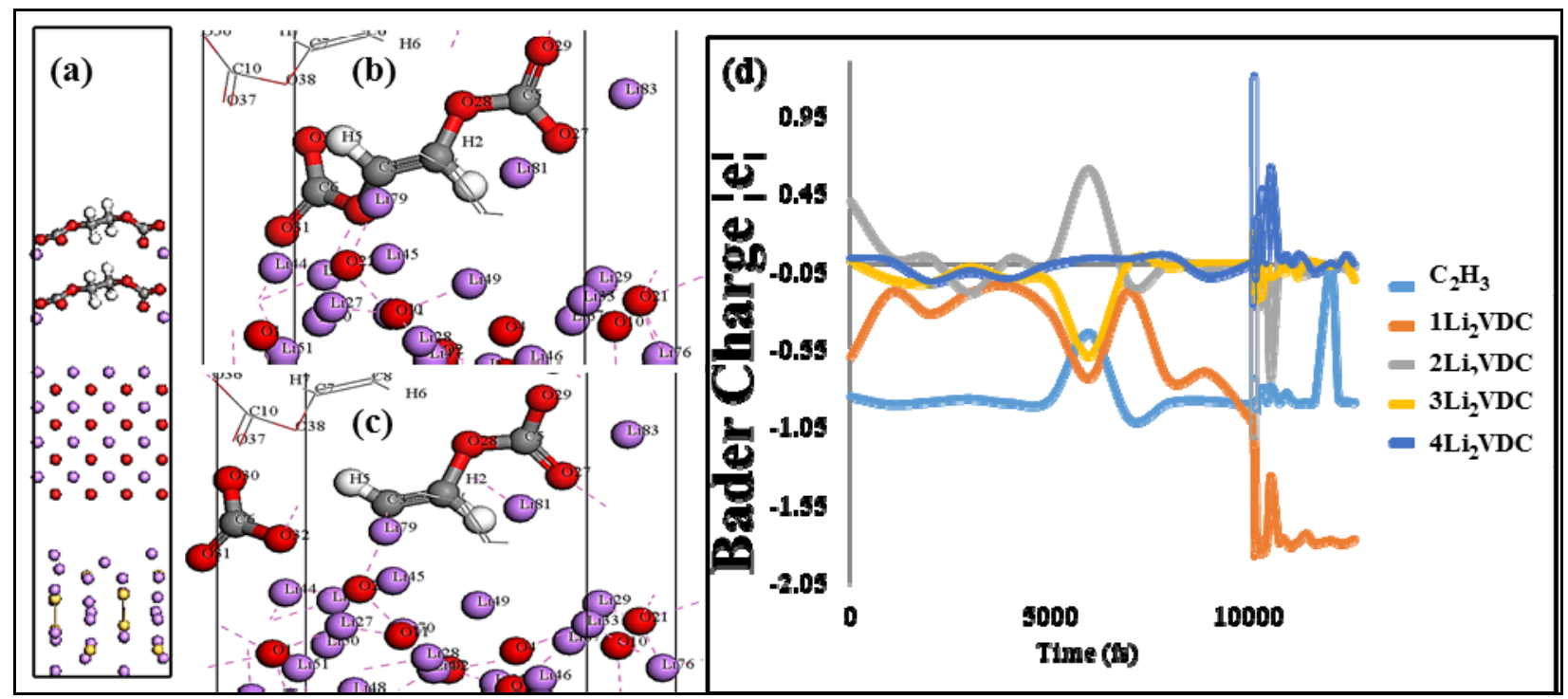

Figure 5. (a) Initial configuration of a model anode/SEI: $\mathrm{Li}_{13} \mathrm{Si}_{4} / \mathrm{Li}_{2} \mathrm{O} / \mathrm{Li}_{2} \mathrm{VDC}$ surface. $\mathrm{A}_{2} \mathrm{H}_{3}$ radical has been added near the $\mathrm{Li}_{2} \mathrm{O}$ surface in the $\mathrm{Li}_{2} \mathrm{VDC}$ region. (b) After 10, $104 \mathrm{fs}$, one of the $\mathrm{Li}_{2} \mathrm{VDC}$ molecules close to the $\mathrm{Li}_{2} \mathrm{O}$ surface starts to be reduced, and the C(vinyl)$\mathrm{O}$ (carbonate) bond elongated. (c) At 10, 115 fs the $\mathrm{C}($ vinyl) $-\mathrm{O}$ (carbonate) bond is broken forming $\mathrm{CO}_{3}$ and a $\mathrm{C}_{2} \mathrm{H}_{2} \mathrm{CO}_{3}$ radical anion. (d) Bader charges evolution for the decomposing molecule (red line) and the surrounding $\mathrm{Li}_{2}$ VDC molecules as well as that of $\mathrm{C}_{2} \mathrm{H}_{3}$. Reproduced with permission from copyright [49•], copyright (C) 2015 American Chemical Society. Color code as in Figure 2.

As previously mentioned, the outer layer of the SEI is mainly formed by a porous organic layer (e.g. $\mathrm{Li}_{2} \mathrm{EDC}, \mathrm{Li}_{2} \mathrm{VDC}$ and so forth). However, this organic layer can easily decompose in the presence of Li atoms [36] or radicals (e.g. OH, $\mathrm{C}_{2} \mathrm{H}_{3}$ ). Since $\mathrm{Li}_{2} \mathrm{EDC}$ and $\mathrm{Li}_{2} \mathrm{VDC}$ play a critical role as an outer layer of the SEI, we showed that these molecules would decompose due to the appearance of radicals in the SEI environment (generated by the reductive decomposition of an EC-based electrolyte). Specifically, the decomposition of $\mathrm{Li}_{2} \mathrm{EDC}$ and $\mathrm{Li}_{2} \mathrm{VDC}$ occurs through the detachment of $\mathrm{CO}_{2}$ and $\mathrm{CO}_{3}$; thus, the SEI growth is triggered by radical anions.

\section{Summary and Concluding Remarks}


Overall, the results we have discussed in this article have important implications for the initial and growth stages of SEI layer formation on Si anodes. Since EC reduces to different adsorbed species and charged fragments at different lithiation stages, the composition of the SEI layer is expected to vary during the first cycling processes. Furthermore, the composition of the SEI layer varies depending on the anode material and decomposed solvent further away from the surface can lead to radical and SEI propagation. Thus, identification of detailed reduction mechanisms of electrolyte components using quantum-based methods is shown as an essential tool for explaining specific characteristics of SEI layers formed on $\mathrm{Si}$ anodes. Finally, the electron transfers from the anode via tunneling would not be possible in a SEI layer that grows thicker than $1 \mathrm{~nm}$. The radical-based mechanism of electron transfer shows that the stability of the products of electrolyte decomposition is the crucial factor that determines SEI growth. These findings are essential for a rational design of Si anode based- rechargeable secondary batteries.

\section{Acknowledgements}

This work was supported by the Assistant Secretary for Energy Efficiency and Renewable Energy, Office of Vehicle Technologies of the U.S. Department of Energy under Contract No. DE-AC02-05CH11231, Subcontract No. 7060634 under the Advanced Batteries Materials Research (BMR) Program, and by the Qatar National Research Fund (QNRF) through the National Priorities Research Program (NPRP 7-162-2-077). PPM and ZL acknowledge financial support from NSF Grant No. 1438431. Computational resources from Texas A\&M Supercomputing Center, Brazos Supercomputing Cluster at Texas A\&M University and from Texas Advanced Computing Center at UT Austin are gratefully acknowledged. 
References

1. Ding Z, Li X, Wei T, Yin Z, Li X: Improved compatibility of graphite anode for lithium ion battery using sulfuric esters. Electrochimica Acta 2016, 196:622-628

2. Foss CEL, Svensson AM, Sunde S, Vullum-Bruer F: Edge/basal/defect ratios in graphite and their influence on the thermal stability of lithium ion batteries. Journal of Power Sources 2016, 317:177183

3. Xu W, Wang J, Ding F, Chen X, Nasybulin E, Zhang Y, Zhang J-G: Lithium metal anodes for rechargeable batteries. Energy \& Environmental Science 2014, 7:513-537

4. Aryanfar A, Brooks DJ, Colussi AJ, Hoffmann MR: Quantifying the dependence of dead lithium losses on the cycling period in lithium metal batteries. Physical Chemistry Chemical Physics 2014, 16:24965-24970

5. Xu Q, Yang Y, Shao H: Substrate effects on Li+ electrodeposition in Li secondary batteries with a competitive kinetics model. Physical Chemistry Chemical Physics 2015, 17:20398-20406

6. Younesi R, Veith GM, Johansson P, Edstrom K, Vegge T: Lithium salts for advanced lithium batteries: Li-metal, Li-O2, and Li-S. Energy \& Environmental Science 2015, 8:1905-1922

7. Kazyak E, Wood KN, Dasgupta NP: Improved Cycle Life and Stability of Lithium Metal Anodes through Ultrathin Atomic Layer Deposition Surface Treatments. Chemistry of Materials 2015, 27:6457-6462

8. Qian J, Henderson WA, Xu W, Bhattacharya P, Engelhard M, Borodin O, Zhang J-G: High rate and stable cycling of lithium metal anode. Nature Communications 2015, 6:6362

9. Deng D: Li-ion batteries: basics, progress, and challenges. Energy Science \& Engineering 2015, 3:385-418

10. Huang Y-Y, Han D, He Y-B, Yun Q, Liu M, Qin X, Li B, Kang F: Si Nanoparticles Intercalated into Interlayers of Slightly Exfoliated Graphite filled by Carbon as Anode with High Volumetric Capacity for Lithium-ion Battery. Electrochimica Acta 2015, 184:364-370

11. Julien C, Mauger A, Zaghib K, Groult H: Comparative Issues of Cathode Materials for Li-Ion Batteries. Inorganics 2014, 2:132 
12. Zhang YJ, Liu XY, Bai WQ, Tang H, Shi SJ, Wang XL, Gu CD, Tu JP: Magnetron sputtering amorphous carbon coatings on metallic lithium: Towards promising anodes for lithium secondary batteries. Journal of Power Sources 2014, 266:43-50

13. Hyun Y, Choi J-Y, Park H-K, Lee C-S: Synthesis and electrochemical performance of ruthenium oxide-coated carbon nanofibers as anode materials for lithium secondary batteries. Applied Surface Science 2016, 2016, http://dx.doi.org/10.1016/j.apsusc.2016.01.095

14. Liu T, Ni H, Song W-L, Fan L-Z: Enhanced electrochemical performance of Li4Ti5O12 as anode material for lithium-ion batteries with different carbons as support. Journal of Alloys and Compounds 2015, 646:189-194

15. Liu Y, Yang Y: Recent Progress of TiO2-Based Anodes for Li Ion Batteries. Journal of Nanomaterials 2016, 2016:1-15.8123652

16. Xie J, Zhang Q: Recent progress in rechargeable lithium batteries with organic materials as promising electrodes. Journal of Materials Chemistry A 2016, 4:7091-7106

17. Roy P, Srivastava SK: Nanostructured anode materials for lithium ion batteries. Journal of Materials Chemistry A 2015, 3:2454-2484

18. Liang B, Liu Y, Xu Y: Silicon-based materials as high capacity anodes for next generation lithium ion batteries. Journal of Power Sources 2014, 267:469-490

19. Ashuri M, He Q, Shaw LL: Silicon as a potential anode material for Li-ion batteries: where size, geometry and structure matter. Nanoscale 2016, 8:74-103

20. Su X, Wu Q, Li J, Xiao X, Lott A, Lu W, Sheldon BW, Wu J: Silicon-Based Nanomaterials for Lithium-Ion Batteries: A Review. Advanced Energy Materials 2014, 4.1300882

21. Zhang M, Zhang T, Ma Y, Chen Y: Latest development of nanostructured Si/C materials for lithium anode studies and applications. Energy Storage Materials 2016, 4:1-14

22. Tian H, Xin F, Wang X, He W, Han W: High capacity group-IV elements (Si, Ge, Sn) based anodes for lithium-ion batteries. Journal of Materiomics 2015, 1:153-169

23. Gu M, He Y, Zheng J, Wang C: Nanoscale silicon as anode for Li-ion batteries: The fundamentals, promises, and challenges. Nano Energy 2015, 17:366-383

24. Xu C, Lindgren F, Philippe B, Gorgoi M, Björefors F, Edström K, Gustafsson T: Improved Performance of the Silicon Anode for Li-Ion Batteries: Understanding the Surface Modification 
Mechanism of Fluoroethylene Carbonate as an Effective Electrolyte Additive. Chemistry of Materials 2015, 27:2591-2599

25. Demirkan MT, Trahey L, Karabacak T: Low-density silicon thin films for lithium-ion battery anodes. Thin Solid Films 2016, 600:126-130

26. Leblanc D, Hovington P, Kim C, Guerfi A, Bélanger D, Zaghib K: Silicon as anode for high-energy lithium ion batteries: From molten ingot to nanoparticles. Journal of Power Sources 2015, 299:529536

27. Wang J, Wang H, Zhang B, Wang Y, Lu S, Zhang X: A Stable Flexible Silicon Nanowire Array as Anode for High-Performance Lithium-ion Batteries. Electrochimica Acta 2015, 176:321-326

28. Martinez de la Hoz JM, Leung K, Balbuena PB: Reduction Mechanisms of Ethylene Carbonate on Si Anodes: Effects of Degree of Lithiation and Nature of Exposed Surface. ACS Applied Materials \& Interfaces 2013, 5:13457-13465

- A key paper that identifies via ab initio molecular dynamics the possible reduction mechanisms of EC at the lithiated Si surface. A key finding of this article is that EC decomposition in the liquid phase is also possible.

29. Martinez de la Hoz JM, Balbuena PB: Reduction mechanisms of additives on Si anodes of Li-ion batteries. Physical chemistry chemical physics : PCCP 2014, 16:17091-17098

- A key paper that shows the possible decomposition mechanisms for widely-used additives such as FEC and VC. It was observed that FEC in some cases, leads to the same decomposition products as VC; which helps to explain similarities in SEI when these solvents are used.

30. Martinez de la Hoz JM, Soto FA, Balbuena PB: Effect of the Electrolyte Composition on SEI Reactions at Si Anodes of Li-Ion Batteries. J. Phys. Chem. C 2015, 7060-7068, 2015, 10.1021/acs.jpcc.5b01228:7060-7068

- This paper predicts through first-principle calculations how electrolyte mixture decomposes, leading to the formation of LiF.

31. Hautier G, Jain A, Ong SP, Kang B, Moore C, Doe R, Ceder G: Phosphates as Lithium-Ion Battery Cathodes: An Evaluation Based on High-Throughput ab Initio Calculations. Chemistry of Materials 2011, 23:3495-3508

32. Jain A, Hautier G, Moore CJ, Ping Ong S, Fischer CC, Mueller T, Persson KA, Ceder G: A highthroughput infrastructure for density functional theory calculations. Computational Materials Science 2011, 50:2295-2310 
33. Piper DM, Evans T, Leung K, Watkins T, Olson J, Kim SC, Han SS, Bhat V, Oh KH, Buttry DA, et al.: Stable silicon-ionic liquid interface for next-generation lithium-ion batteries. Nature Communications 2015, 6:6230

34. Zhang S, He M, Su C-C, Zhang Z: Advanced electrolyte/additive for lithium-ion batteries with silicon anode. Current Opinion in Chemical Engineering 2016, 13:24-35

35. Leung K, Rempe SB, Foster ME, Ma Y, Martinez-delaHoz JM, Sai N, Balbuena PB: Modeling Electrochemical Decomposition of Fluoroethylene Carbonate on Silicon Anode Surfaces in Lithium Ion Batteries. J. Electrochem. Soc. 2014, 3:A213-221

36. Kim S-P, Duin ACTv, Shenoy VB: Effect of electrolytes on the structure and evolution of the solid electrolyte interphase (SEI) in Li-ion batteries: A molecular dynamics study. Journal of Power Sources 2011, 196:8590-8597

37. Haregewoin AM, Leggesse EG, Jiang J-C, Wang F-M, Hwang B-J, Lin SD: Comparative Study on the Solid Electrolyte Interface Formation by the Reduction of Alkyl Carbonates in Lithium ion Battery. Electrochimica Acta 2014, 136:274-285

38. Jorn R, Kumar R, Abraham DP, Voth GA: Atomistic Modeling of the Electrode-Electrolyte Interface in Li-Ion Energy Storage Systems: Electrolyte Structuring. The Journal of Physical Chemistry C 2013, 117:3747-3761

39. Gourdin G, Collins J, Zheng D, Foster M, Qu D: Spectroscopic Compositional Analysis of Electrolyte during Initial SEI Layer Formation. The Journal of Physical Chemistry C 2014, 118: $17383-17394$

40. Borodin O, Bedrov D: Interfacial Structure and Dynamics of the Lithium Alkyl Dicarbonate SEI Components in Contact with the Lithium Battery Electrolyte. The Journal of Physical Chemistry C 2014, 118:18362-18371

41. Tasaki K: Solvent Decompositions and Physical Properties of Decomposition Compounds in LiIon Battery Electrolytes Studied by DFT Calculations and Molecular Dynamics Simulations. The Journal of Physical Chemistry B 2005, 109:2920-2933

42. David L, Bernard S, Gervais C, Miele P, Singh G: Facile Synthesis and High Rate Capability of Silicon Carbonitride/Boron Nitride Composite with a Sheet-Like Morphology. The Journal of Physical Chemistry C 2015, 119:2783-2791

43. Li X, Wang X, Li S: Silicon anode supported by carbon scaffold for high performance lithium ion micro-battery. In Micro Electro Mechanical Systems (MEMS), 2015 28th IEEE International Conference on 18-22 Jan. 2015: 2015:130-133. 
44. Liu N, Lu Z, Zhao J, McDowell MT, Lee H-W, Zhao W, Cui Y: A pomegranate-inspired nanoscale design for large-volume-change lithium battery anodes. Nat Nano 2014, 9:187-192

45. Ma Y, Martinez de la Hoz JM, Angarita I, Berrio-Sanchez JM, Benitez L, Seminario JM, Son S-B, Lee S-H, George SM, Ban C, et al.: Structure and Reactivity of Alucone-Coated Films on Si and LixSiy Surfaces. ACS Applied Materials \& Interfaces 2015, 7:11948-11955

46. Mi H, Li F, He C, Chai X, Zhang Q, Li C, Li Y, Liu J: Three-dimensional network structure of silicon-graphene-polyaniline composites as high performance anodes for Lithium-ion batteries. Electrochimica Acta 2016, 190:1032-1040

47. Soleimani-Amiri S, Safiabadi Tali SA, Azimi S, Sanaee Z, Mohajerzadeh S: Highly featured amorphous silicon nanorod arrays for high-performance lithium-ion batteries. Applied Physics Letters 2014, 105:193903

48. Sandu G, Brassart L, Gohy J-F, Pardoen T, Melinte S, Vlad A: Surface Coating Mediated Swelling and Fracture of Silicon Nanowires during Lithiation. ACS Nano 2014, 8:9427-9436

49. Soto FA, Ma Y, Martinez de la Hoz JM, Seminario JM, Balbuena PB: Formation and Growth Mechanisms of Solid-Electrolyte Interphase Layers in Rechargeable Batteries. Chemistry of Materials 2015, 27:7990-8000

-With ab initio molecular dynamics simulations longer than $100 \mathrm{ps}$, this work shows that the instability of electrolyte decomposition products. Thus, the key to obtaining a good SEI layer is the stability of these products.

50. Leung K, Soto F, Hankins K, Balbuena PB, Harrison KL: Stability of Solid Electrolyte Interphase Components on Lithium Metal and Reactive Anode Material Surfaces. The Journal of Physical Chemistry C 2016, 120:6302-6313

51. Benitez L, Cristancho D, Seminario JM, Martinez de la Hoz JM, Balbuena PB: Electron transfer through solid-electrolyte-interphase layers formed on $\mathrm{Si}$ anodes of $\mathrm{Li}$-ion batteries. Electrochimica Acta 2014, 140:250-257

- Using DFT/Green's calculations this work shows that electron transfer from the anode via tunneling would not be possible after the SEI layer grows beyond $1 \mathrm{~nm}$. 